\title{
Social Systems: Structure, Development and Application of the Fibonacci Sequence
}

\author{
Pavel Brazhnikov \\ Scientific Academy for Research of Social and Psychological Systems, Moscow, Russia \\ Email address: \\ br@zhnikov.com

\section{To cite this article:} \\ Pavel Brazhnikov. Social Systems: Structure, Development and Application of the Fibonacci Sequence. Economics. \\ Vol. 10, No. 1, 2021, pp. 28-39. doi: 10.11648/j.eco.20211001.14
}

Received: January 8, 2021; Accepted: January 15, 2021; Published: February 23, 2021

\begin{abstract}
This article presents description of social structures such as, for example, states, in the context of their consideration as systems. Moreover, it seeks to develop K. Marx's model in terms of systematic approach, as well as to justify the application of the Fibonacci sequence to systems in general and, in particular, to social systems. The description covers a wide range of issues, ranging from the assertion of the basic principle of living systems as patterns in resources flows to description of functions of various aspects of states and their economics in terms of objective needs of such structures. In addition, this article justifies synergetic effect based on proposed model, and the way this effect is applied to state systems. Moreover, it includes the description of main changes of socio-economic formations throughout the history as a natural development of social systems, including possible modern stages. The fundamental tool of this description is description of essence of the mechanism of property rights and its formation options. The differences of two extreme directions of such development are also described on the basis of the objective factor of resource provision. Special attention is given to the concept of surplus value as a feature of social production systems.
\end{abstract}

Keywords: Economic Systems, Social Structure, Ownership, The Fibonacci Sequence, Surplus Value

\section{Introduction}

This article was written with an aim to offer a small addition to the systems theory and to expand the materialistic approach to economics.

We should start with an overview of general concepts. There are many definitions of systems and living systems, and in this article a living system is defined as a regularity in flows of matter or energy (resources). In the article we will only talk about living systems, including the most complex of them, social systems. All systems are composed of matter (or energy) and are in motion. Repeating and self-sustaining patterns in matter and energy flows, which spend part of their resources to maintain themselves in the future, are most stable flows [1], and they are living systems.

The most efficient way to maintain systems is to expand their resources flows constantly, which means the increasing of their efficiency. In most cases, the increasing of efficiency is related to increased complexity $[2,3]$, since there emerge mechanisms for exploitation of previously untapped types of resources, which join the total flow through systems.
Self-replication is one of the basic mechanism that systems use for their self-preservation [4], as it reduces consequences of individual copies destruction and creates the possibility for evolution by selection. Another mechanism on which systems stability and self-sustaining of resources flows depend is the pursuit of predictability of resources flows [5]. Under normal conditions, which are with lack of full information on the environment, the need to avoid changes is a very effective way of self-preservation.

As stated above, in this article systems are defined as patterns in resources flows. All living systems are incorporated into larger flows of resources and encompass a number of smaller flows of matter and energy within themselves. Some of these flows are living systems too. Being part of large flows systems receive resources and then pass them on. Every interaction is bilateral; there is an exchange of various types of resources. All parties engaged in such exchange are in need of resources received to maintain their internal flows and have the resources, which the counterparty requires.

Since the exact quantitative match of current demands to 
existing supply is impossible, one of the parts will continue to experience resources shortage after their interaction and will be in need of new exchanges with other counterparties. Accordingly, the other side will receive more resources than it needs. Excessive resources are used to expand a system that is to increase the number of its component elements. With regard to the sources of scarce resources, there will be an aspiration to maintain and enhance connection with them. Strengthening ties with counterparties means that the interaction efficiency will be increased due to a greater qualitative conformity with demands of the opposite side.

It is important that the maximum system resources will be diverted to enhance the efficiency, since otherwise there is a higher risk that rival systems will spend more resources and win in this struggle. The maximum effective level of resources, which could be spent profitably in a certain direction, is equal to a possible gain. High expenses will not be justified and will lead to a system loss, that is to say to the damping of part of its matter and energy flows. Thus, the costs are on average equal to the total benefit of those systems which will choose the right direction for their evolution. Other systems will waste their resources in vain. As applied to economic social systems this rule could be reformulated as follows: the value of all goods in a market system is equal to the value into price of their production [6].

\section{Norms}

The most developed systems use integrated resources of diverse nature to maintain their existence. Resources utilized by humans are very diverse: there are food, air, light, materials, information, social resources and other. Let us consider social resources in more detail. In this article social resources are defined as an opportunity to use for a personal benefit the facilities of groups of people to which a person belongs, or, in other words, the resources of special systems this person forms part of. Accordingly, as soon as a particular sphere becomes available to the system as resources, it is also becoming a source of risks. In addition, the social sphere has relevant social risks, for example, there is a probability to be excluded from any useful group of people.

The two main mechanisms of self-sustaining reviewed above are also true to social systems. Small systems strive to spread themselves among a large number of people who are not integrated in them at the current moment, and strive to a predictable human behavior who form a social group. Large social systems which include more than a half of people of the next larger set in the hierarchy are seek to increase a number of people, their components and to gain the predictability of all others. There is a need to clarify the division of systems on small and large ones that has just been applied and will be applied further in this article. Small systems are sets, which include less than a half of elements of the closest large set and which forms part of it. The large ones include more than a half. Specific features of a system are in the differences between its elements and the elements of a large set. Such differences separate its internal elements from external. The wider the set, the higher the probability of deviation of the characteristics of its elements from the mean, and the broader the range of values. To define a system through the description of its differences it will be more effective to describe the characteristics of small set. For small systems a small set is characteristic of the system itself, and for major systems, it is characteristic of its exceptions. In an abstract definition, it looks like one thing, but in practice, every self-sustaining system should filter its elements from the others, which means controlling the relevant characteristics. It therefore seems that in the case of systems the number of parameters monitored directly affects the resources expenditure and the general systems efficiency.

Participants of social systems being a part of them, transmit the goals of their systems [7]. Social systems are sets of people, which are formed due to the ties of people who are similar in a way, and whose patterns of interaction with the world are close in some area. Accordingly, the maintenance of all systemically important properties by all participants of a system is a factor of system maintaining and conforming social resources preservation. This is a result of a need for predictability of system components.

For large social systems, which are sets that include more than a half of people of the closest large set, it will be more cost-effective to determine the patterns, which are not appropriate for their components. That is, to determine parameters characterizing the exceptions to the set.

The larger the set of people united by a system, the higher the risk of deviation from the reference value of systemically important characteristics of people. Therefore, the less specific could be requirements for them or for the exceptions to such sets. The ambiguity of requirements creates the situation of risks uncertainty due to deviation from the mean. Herewith, some systems may be of critical importance for some individuals, if they depend on the resources providing their basic physical needs.

When unified resources flows of several people consolidate into a common flow, the fluctuations of the total flow less affect individuals, increasing their resilience in different situations [8]. For this reason, social systems formed by many people with a similar source of core resources and focused on their stable obtaining, are most important for its participants. The requirements for participants of mentioned social systems have always been the first thing to recorder throughout our history in various forms such as customs, religious requirements, law and others [9-11].

All the requirements of social systems being fixated in any form should have a source that is a subsystem which determines optimal requirements in a current state of an environment. But also there is a need for mechanisms of temporary or permanent exclusion from system of those elements that do not meet the requirements. Therefore, social risks not only depend on probability of the requirements violation, but also on the probability of use of sanctions in the case of their violation. Also, as it is impossible to formalize requirements of the system perfectly accurate, 
there is a need for mechanism for their interpretation in insufficiently detailed formalized cases of requirements deviation. These are the reasons for the need of legislative, executive and juridical mechanisms in any social system.

The analyzed examples of internal mechanisms of social systems have analogs in all other self-sustaining systems. Such functions are performed by a part of set elements, and thus, they compose a some subset. The existence of such internal mechanisms is an example of internal specialization of system elements that allows reducing duplication of functions and the costs of switching between different functions for certain system elements. It is through this the effect of synergy could be achieved in systems, whereby a set reaches the level of effectiveness which is higher than a total effectiveness of its elements [12].

Now it worth consider social systems organized on the basis of less critical characteristics of people. Such systems formalize their requirements less frequently [13], as with priority given to systems that are more critical, there are no resources for specific monitoring mechanisms and all participants of system carry out these responsibilities by themselves. First, that means that they should articulate the requirements for the members of group, they should monitor their compliance and interpret controversial cases.

The grounds for an independent formation of such requirements could be personal experience, opinions of the other members of group and other subjective factors [14-16]. The monitoring mechanisms are limited only by the capabilities of person himself. These mechanisms include sanctions against the members of group who according to the person opinion infringed the group norms, and rewards for those who comply with the requirements. Every member of group expects that the appropriate monitoring mechanisms be applied by the others member of group. However, since the requirements of such groups and possible sanctions are not clearly defined, the risks after violation of such requirements are uncertain. Neither the upper limit of the possible consequences, nor the probability of the absence of effects. The existence of unknown risks leads to the need to channel the possible maximum of resources to address them by comply with the rules. For that reason, the range of compliance with the requirements of various social groups could vary widely even for one person. It differs depending on the importance perception of a particular social group in a particular moment as well as on how much resources will remain after addressing the personal needs of higher priority.

The situation is different with the groups, which have their requirements articulated in any form. In that case, the members of group could more reasonably assess the consequences of aberration. It is pertinent to give one of the classic examples [17]: there was imposed the fine for being late in some kindergarten. After that the number of delayed was doubled. It could be interpreted as that before the fine imposition punctuality was not formally articulated requirement of some social group with unknown risks, but after the fines have been introduced it became the requirement with formalized consequences which was made possible to assess. Moreover, apparently, that in described example the consequences were not of high significance.

This example also provides an illustration of how an unspoken requirement of a social group to be punctual was withdrawn. Having become a formalized requirement that applies to all clients of kindergarten, it was no longer a rule characterizing social subgroups among the kindergarten clients.

Now let us return to social systems with fixed requirements. As mentioned above, the requirements of social groups, which relate to the basic needs of people, are fixed in the first place. The needs of having food, safety and health are among such needs. That is why rules related to such areas and relevant institutes emerge first. With achieving a sufficient account of complexity of some social process, especially concerning production, the same rules applied here that is to fix the norms and the mechanisms for monitoring requirements for participants of main social processes.

However, it is often required to change quickly the requirements for the group members - that is an operational management. This requires mechanisms that do not fix the rules themselves, but fix their source, which exercises operational management and controls a certain group of people, for example, a household, a parish, a workshop and others. When there are a lot of such groups, there is a set of leaders formed, so it will be more effective to fix their functions with a single mechanism - that is with a general statute and with a consolidated control and protection of these functions. In this case, there is a unified system of production emerging in a state. Herewith, owning to the limited capacities of monitoring, such a mechanism could be applied only to the most common industrial relations, or those related to the largest flows of resources. In fact, production systems becoming large in a society, declare their norms as common rules, creating certain rules for small subsystems, if necessary.

The mechanism of securing the right of operating control over production process most frequently secured through the property. Ownership is composed of three aspects: the right of disposal, use and possession [18]. The right of disposal consists in the right to determine the fate of an object. The right of use means to benefit from an object. The right of possession is the right to manipulate a thing. Two last components of the right could be fully delegated. Let us consider where the right of ownership could be extended in detail.

\section{Ownership}

Historically, at the beginning the main resources were collected in their natural form: wild plant, animals, honey, meteorites or surface metals and etc. Then the ownership could be extended only to main personal tools and territory, where resources could be obtained. It is still unknown how ancients society were organized, but modern examples at a similar level of production development allow us to suggest 
that it was collective ownership and it extended on territory as wells as on tools. Thus, a current representative of collective provided operational management, who represented a collective as the owner of resources. Often it was an elected position. In such circumstances a collective determined its representatives who directly exercised the collective right of ownership that is the collection of resources. However, this is not a delegation of right of possession, but the realization of this right by a collective itself. The right of use and the right of disposal also were left for the whole collective. The individual ownership unlikely existed in those times in view of relatively high complexity of its ensuring.

Later, probably due to the exhaustion of available resources, people had to develop methods for its replenishment, like to domesticate plants and animals, to develop metal mining and alloy creation techniques $[19,20]$. The costs of such replenishment of resources in the future or infrastructure have a long-term cost-recovery. That is why such costs require making a choice between long-term and current benefits. Since the goal of a person as a system is to increase the predictability, as a rule an individual will tend to invest in future income. However, if the risk-adjusted investments were higher than the potential benefits, it would be preferable to save resources in another way.

When sources of resources are scarce, the risk of their even temporary reducing poses a critical danger. For this reason, under conditions of shortage, there is a need of mechanisms enhancing predictability and sustainability, that is to create a larger system for synergies and investment into the future flows of resources. If the sources of resources significantly exceed the needs, than the risks associated with their temporary reducing are not critical. Therefore, under conditions of a certain surplus it is not safety of resources sources in the future became valuable, but their intensity. That means that, in first place, the investments would not be channeled for maintenance of the super system, but for the expanding of the system itself. Security and intensity are contradictory areas of investments, as high benefits involve high risks and vice versa.

In other words, with scares resources there will be developed a collective ownership, when many people are almost equally involved in the distribution of benefits. In a more abundant environment, there will be an individual ownership, when the distribution of benefits among individual representatives depends on their personal share, or property value.

Let us return to the issue of investments to replenish resources. The benefit of long-term investments will be more profitable, if it accompanies the right of disposal, then the owner is interested in the rechanneling of benefits back to the source development, to secure it or to intensify it. Such system will be more sustainable in a long-term perspective. Thus, after the transition from simple collection of primary resources in their natural form to their maintenance, there emerge an individual ownership, if there is an abundant environment. Then, there two possible types of organization of operational management appear - collective management through its temporary representatives and individual leadership by a sole proprietor. In both cases, the right to possess of renewable resources, such as land, cattle, mines and others. The transition to a system of organization with delegation of right of possession and with collective ownership corresponds to the so-called Neolithic revolution [21]. When, with the development of technologies and increasing amount of resources, social systems with individual property instead of collective appear, the dependence of workers on landowners and tools grows, which probably served as the basis for the slavery $[22,23]$.

With a further technological development, ways to enhance the effectiveness start evolving at the expense of specific means, which have a short term of use or action, depending on the way of use. It could be fragile tools, which requires special care, or methods for maintaining animal health. As the requirements for control of work quality are increasing everywhere, the former methods of organization will not ensure the maximum effectiveness. To create an extra level of control, that is to create a need for it, the mechanism of delegation of the right of use is being developed, that means a right to extract useful benefits of an object. With such an organization, the employee's benefit depends on the costs of maintaining of means of work. That is, probably, the main reason of the Feudal Revolution. At the same time, formalized norms are still remained being focused on maintaining the leading role of the owner of renewable primary resources (of land, cattle, mines and others) irrespective of collective or individual ownership, but were complemented with norms for maintaining the rights of users of property.

The major update of norms occurs, probably in that time, when the total flow of resources which is passing through the subsystem of owners who delegate the right of use, surpass the flow of resources of subsystem of owners who delegate only the right of possession. Than the subset of manufacturers with a new distribution of the ownership' components became more important for people and the relevant laws are reaching a critical importance. Such objects instead of being a small system evolve in a large system, which covers more than a half of the economy of society.

With the subsequent development of technologies, an increasing part of the work of individuals is carried out by specialized subsets. Among those types of work are trading, tools and household item manufacturing, textile production, processing of primary resources, for example, the processing grains into flour. It saves time on work and on switching between activities. Thus, there is more time remains for the main work. At a certain level of technological development, the benefit of external manufacturing services surpasses the income received without using of them. Thus, it is worth to give more than a half of extracted resources to pay for such services, since its benefits are higher. Moreover, that means that the flow of resources coming through a field of concomitant production is bigger. This area is becoming crucial for a social system and there emerge laws, protecting 
key industry leaders that are the owners of concomitant means. Thus, the owner by hiring workers delegate them the right to possess the means of concomitant production. Such a shift of priority in laws of various countries could be linked to the end of feudalism and the Church authority, and to the beginning of the Industrial Revolution and the promotion of mercantilist policy. The most striking example of such a transition is the textile industry [24]. However, an earlier similar transition had place in maritime trade [25], where functionally, a merchant ship is a mean of concomitant production applied to the natural resource of trade routes. At an early stage, the ownership of the trade routes territory allowed to get profit from the delegation of the right of possession, i.e. of passage of ships. Subsequently, the technological development pushed the boundaries of trading so far, it were the merchant ships that became the main source of profit in this area, and their owners were able to delegate their right of possession of ship by hiring a crew.

Then there is a certain process take place, which is identical to development of delegation of the ownership on the territory with primal resources components. With the methods of concomitant production evolving, it covers even greater spheres of life. Starting from the most basic and stable, eventually it goes to rather mutable spheres, where needs more depend on the situation: logistic providing, insurance services or technique manufacturing - areas, where even small changes could significantly change the demand. That is, again there is a need to increase operational control to accelerate the reactions to the market changes. To this end, as it was earlier, the mechanisms of the right of use delegation are also being developed, which increases the interest in maintaining efficiency. Over time, the value of resources flows passing through more mobile organizations using delegation of the right of use exceeds the flow passing through old-style organization that delegate only the right of possession. In other words, the benefits of a quick response to changes exceed the potential benefits of production that responded much slower. In that case, the new organization becomes more important for a social system. Therefore, such system develops relevant norms and institutions to protect them, in the first place, such as the securities market. Then there is the shift of the priority of legislation and other institutions from delegating only the right to possess the means of concomitant production to the delegation of right of use when the owners only financially involved into the enterprise, rarely making significant decisions about it [2628]. Herewith, maritime trading was among the first industries made this transition, switching to the delegation of the right of use by ship owners.

It is more difficult to describe further revolutionary changes in social systems because they began to spread recently. It can be assumed that these changes are linked to the fact that with the increase of production efficiency and its scale growth the need for primary resources or for financial services has grown so much, that their sustainability has become critical. Therefore, the methods of productive integration are developing with which the sources of primary commodity necessary for the production of tools are tied stably to a specific production. The owner delegate the right of possession of a single chain to the workers if the proprietor has the ownership of sources of primary commodities, financial institutions and tool manufacturing capacities [29].

With a further rising of competition, the concentration of ownership of a group of companies has become less profitable, since it requires large financial expenses and limits the ability to attract external participants. Therefore, the practice of increasing the number of small shareholders is becoming more widespread [30], because they cannot fully participate in the management of organizations even with a high share of financial participation. With such distribution, the right of disposal is retained by one main owner, even with a small amount of the funds he or she invested in the organization, but external participants are significantly more involved into the company activities and they depend on it. This transition of state priorities took place in the most economically developed countries in the middle of the 20th century.

Further, probably when demand for goods began falling short of supply mechanism of delivering products to consumers and demand management started to play a significant role. Exactly as it was before, the production of additional tools has been separated from their scope substantially. As the effect of interaction with consumers increases, so does the profit share, which is beneficial to give for such services. Legislation priorities are changing relevantly. It is highly probable that this is the core issue of the next revolution - the activity of the owners of communication channels with consumers of the majority of concomitant would be moved-up to the first place. The basic issue related to such ownership is delegation of the right to possess the audience to employees.

Then by analogy, we could expect that the next revolution will reflect the fact that due to the increasing need of more effective control there is a growing need to delegate the right to use communication platforms with users. The one of illustrations of this trend is the fact that nowadays more and more information is passing through such platforms on the Internet.

\section{Difference Between Centralized and Competitive Systems}

As stated before, social systems could have different priorities depending on their resource base [31]. With scare resources, they would be centralized to increase their security through the maximum synergy. With a relatively abundant environment for many areas the main priority will not be security, but personal gain, that is the competition will prevail, increasing the probability of developing of more advance mechanisms of adaptation to the environment. In such cases, competition is possible due to the fact, that even with a slight chance of winning, the gain value has the 
potential to recoup even large investments. Moreover, a loss in competition does not result in death, since it is easy to replenish a necessary minimum in an abundant environment. This is one of the main pillars of competition in such systems.

Of course, competition does not manifest in all areas. For example, at some levels a subset of the most successful participants in the social system will cooperate to develop protection mechanisms against other subsystems. In addition, other subsets will also show signs of centralization. However, the higher the average level of resources per one member of the set exceeds the minimum requirements, the less the need for centralization and the more areas acquire the features of competition for the value of individual resources with a minimum share of cooperation. Primarily competition will appear in a subset of owners, which is a priority of the norms of the social system, as it is best endowed with resources. The emergence of competition or centralization in the subset of large system, through which the main flows of resources pass, makes it possible to generalize its priorities to the whole set, since that is its priorities that are leading for the entire social system. At the same time, as mentioned above, properties of such subsets of participants are changing with technological development.

In the process of system expanding that is with an increase in the number of participants the both types of systems centralized and competitive will enhance their priority characteristics. Centralized systems, due to the need to coordinate and control more elements of many people, will develop relevant mechanisms and their hierarchy. Moreover, along with the hierarchy of functions, the hierarchy of subsets of people performing these functions will grow too.

Competitive systems with the growth of participants, and hence with an increase in the total volume of resource extraction, will increase the volume of individual appropriation of resources of the most successful in competition systems participants. Along with that the potential gains in competition will also grow, and hence the incentives to participate in it. Of course, both types of systems when changing the resource base are able to chance their direction for the opposite type of systems.

We have described the division of systems into systems with a priority of sustainability, and, therefore, of centralization, and systems with a priority of greater benefit, or a priority of competition. This description has been made for isolated systems. Now let us consider cases of interaction between systems.

If there are two systems with similar priorities, one of them will always be more developed, since there could not be two identical systems. Thus, in one of two similar systems, the possible sustainability or possible gain will be higher. Then, for a less developed system, it will be more advantageous to join fully a more developed one. A more developed system will also benefit if it includes new participants, as it will enable a quicker development. At the same time, the concentration center of maximum benefit or maximum centralization will remain in a subset of the elements of a more developed system. This consolidation will also lower the average benefits or average importance of centers in a subset of the elements of a less developed social system.

The situation is a bit more complicated when it comes to two opposite systems, since the comparison of their development is not so obvious. In this case, it is necessary to compare the effective flow of resources through systems to evaluate the result of their interaction. In this article effective resources flow will be defined as a resource flow aimed at maintaining the priority direction of a social system, competition or centralization. In a centralized system, the most part of resources is channeled to maintain sustainability, after deducting some transmission losses between elements of the set. However, often those losses could not compare to the synergistic effect. In a competitive environment, almost all resources are directed to increase benefits, but as a result, only a relatively small part of the resources is effectively spent.

Let us explain the reason for the high losses in competitive systems. To increase benefits, it is necessary that the efficiency of methods for obtaining resources exceed the effectiveness of competitors. However, since new methods are spreading fast enough, the development of more profitable methods for obtaining resources is constantly required. In its turn, there is a need to spend resources on changing current action algorithms. Along with that, it is impossible to predict the result of changes in the conditions of uncertainty. That means that many modifications will be made in wrong direction and the resources spent on them will be wasted. Such social subsystems will disappear, and their participants will join the more successful ones. This results in a high percentage of losses due to high risks with large wins in competitive systems.

For the reasons described, that means that a centralized social system can be comparable in terms of the effective resources flow to a competitive social system, and is even superior by level of development. However, a significant difference in development will lead to the fact that either the possible reliability or the possible gain will be significantly higher than the offer of a competitor and one of the systems will absorb another one, as in the case of unidirectional systems.

Moreover, if two opposite systems interact, then the interaction occurs at all levels of the subsystems. Therefore, the most developed subsystems will be much more likely to appear and concentrate in a competitive social system, for the reasons described above. And vice versa, those subsystems that require sustainability will gravitate towards a centralized social system. That is, with the coexistence of a centralized and competitive system, the competitive system will accumulate the most developed subsystems. However, as soon as some subsystems cease to be the most developed in terms of organization and there starts the process of their replacement by more efficient ones, they can remain successful in a subsystem with the opposite type of organization. This is possible due to the fact, that while such subsystems were the most developed, they were concentrated 
in a competitive environment, but after the beginning of their displacement, the competitive environment ceased to be attractive for investing their resources and they redirect resources to a centralized system in search of reliability. However, despite the absence of the most effective subsystems, a centralized system is usually more developed in terms of organization.

At the beginning it benefits a centralized system to include more developed production subsystems while maintaining the priority of the outdated main production method. Nevertheless, as soon as they capture a significant share of the resources flows, they begin to strive to change the legislative priorities of the social system. Then a change of priorities - or revolution - takes place, but all new and more developed subsystems become centralized and form the basis for the further development of a centralized system. Then, in centralized systems, new ways to organize the ownership structure gain greater development depth.

The Russian Revolution at the beginning of the 20th century is one of the relatively recent and described in detail examples. At first, individual bourgeois revolution took place [32], when the owners of the means of concomitant production changed the priority of the state of the owners of the sources of primary resources that is feudal lords. In addition, a few months later, the collectively bourgeois revolution took place, with a priority for centralized management of most of the means of concomitant production [33], [34], with the state as a collective owner. Then the state largely centralized delegated the right to possess the concomitant means of production - it hired workers by itself. Then there has been established a collective bourgeois system, when citizens, founders of the state, hire themselves through their representatives. This moment, accordingly, coincided with the time when the first competitive capitalist states with the delegation of ownership of production chains were clearly formed.

The most recent changes in the organizational structure in such countries took place when in the most developed in terms of organization competitive countries, the change of state priorities to owners of means of communication with consumers began. Then in large countries, such as, for example, Russia and China, elements of state capitalism start appearing, that is when a state is the main shareholder of major part of highly integrated industries. That means that besides the right of possession a state delegates the right to use the means of concomitant production.

\section{Surplus Value}

When Karl Marx described a communist society, which should replace capitalist, in fact, he described a collectively bourgeois state system, when workers hiring themselves and there is no excessive competition [35]. However, he believed that the main drawback of the individual bourgeois system is the appropriation of a part of the surplus value produced by the workers by the capitalists. Let us consider what surplus value is more closely. To do this, first we should briefly consider the development of production.

Initially, people received those resources that he directly spent energy on to require them, primary resources in its natural form: wild animals and plants, and natural materials. That is, there were some resources sources, from which a person took part for his needs. Then people began to create tools, dwellings, clothes, etc., introducing a new order into the world around him. In fact, the humans started creating new patterns in the existing resource flows.

Everything that has been created by the person has a potentially infinite lifespan, if maintained in good condition. Except for objects, created with the use of short-lived materials. That is, additional patterns, modulations introduced into existing resource flows, if supported, in theory can exist forever, except for modulations introduced into initially damped processes. In some respects, information tools are special: having no carriers other than human memory, they depend only on maintaining transmission between people. Among such objects are language, numbers, calculations, writing and any other information.

Once created, the products of human activity, new patterns in the world, combined with human action can carry out part of the work that is useful for a person. That is the way by which both simple tools, even a simple stone, and information tools, for example, previously developed resource acquisition algorithms, work. So, the transition from simple collection of primary resources to their renewal became possible after the development of relevant methods that work, in fact nowadays, bringing additional benefits to people. Previously created tools bring additional resources flows to humanity for a long time, which is potentially unlimited for some tools. This is the effect that creates increased labor productivity. Almost constant value of efforts of individuals, combined with the effect of previously created tools, brings much more benefits. Previously created tools require maintenance to enable their using to continue. Those tools, which were created from external to people materials, require certain efforts to maintain their integrity. Information resources also require efforts to preserve the possibility of their use. Not just the knowledge of algorithms or mechanisms, but even the languages of communication can disappear if they are not used and transmitted.

Moreover, all tools require their delivery to the object of its application. It concerns not only the classical material tools, but also the information ones. For their use the last ones should be known to people using them, that is often turns out to be challenging in the light of the narrow range of use of such informational tools, for example such as knowledge of specialized technology, or deep knowledge of the narrow branches of any sciences. In fact, a knowledge holder provides the delivery of information tools to an object of its application.

The employees' payment corresponds to their personal efforts and the kind of tools they can use: as a driver with his car costs more, so a worker with education and experience costs more. The amount of the premium to pay for individual 
efforts corresponds to the cost of maintaining the tools brought by the employee into the activity.

Tools could differ by its range of action, that is, in the proportion of people whose productivity they increase. Here some examples of broad in application tools: speech, which increases the effectiveness of coordination between participants in social systems; numbers that increase the speed of calculation; nuclear power plants providing energy to several cities; nails manufacturing technology or crawl swimming technique. The tools of targeted action are more specialized, like professional knowledge and equipment.

The norms of interaction between participants in social systems, including state legislation, are tools of broad application that increase the efficiency of the entire social system and increase total resource flows. However, this information tool cannot be applied individually, but only by a social system of sufficient volume in order to create relevant specialized subsystems to ensure compliance with standards. A part of the additional income from such instruments should be channeled towards their maintenance, as in other cases.

As mentioned above, ownership according to the proposed model is necessary to determine who is responsible for tools management. Accordingly, when tools that increased the productivity of several people appeared, there was a need to organize the process of using these tools. The more the leader interested in the effective use of the tool, the more effective the leadership. That is, the stability of the tool as a system will be beneficial to the organizer of the use process, if the tool forms part of the system of the organizer of the use process. Then the stability of the personal system of the organizer of the process of using the tool directly depends on the stability of tool's work. This is the type of connection between the organizer and the tool that the institution of property creates, regardless of whether the property is individual or collective. The right of possession and use may be delegated. However, while retaining the right of disposal, temporary holders of ownership are dependent on the owner and may be replaced. Moreover, in most cases a group of owners that has a collective ownership appoints one of the participants as their representative, temporarily delegating to him a substantial part of the right to dispose.

All resources flows generated with tools using, either pass directly through the owner, or with development of society, are controlled by the owner, directly or indirectly. The owner directs these resource flows to maintain sustainable operation, as well as to further development and upgrade of tools' range. If the organization of resource flows is not effective enough, then other members of the society from the subsystem of owners or their representatives will replace the underperforming ones in the process of competition.

All resource flows added to the individual work of an individual worker are forming of various tools. These tools can be divided into material and informational, as well as those provided to the workers and presented from the outside. Those tools that have a wide range of applications, that is could be used by more than one person, in most cases require maintenance, regardless of whether they are material or informational. Thus, they probably have an owner, a collective or an individual one.

Such tools as language, writing, counting and the like are usually belong to collective owners that provide a collectively maintenance. Often such maintenance is provided through special institutions like free basic education, the resources for which are collected from all participants of the corresponding social system. In addition, many other information tools usually have a collective owner, and therefore are supported and developed at the expense of all participants of the corresponding social system, among them are laws, education, science, culture and others. The same is true for many material tools: roads, public buildings, structures and other infrastructure. Social systems maintain such tools through relevant institutions, or specialized subsystems.

It should be noted that the institution of property is also an information tool that is supported collectively. The choice of objects in a private or collective version is chosen by the social system itself. The participants in the social system also choose the shift of priority in the activity of property protection institutions, but such a change may occur in various ways.

When a tool is individually owned, the responsibility for its maintaining is individual. The owner, gaining all the resources produced using the tool, redistributes them in a way to maintain a stable work in the future: paying employees for their personal work and the work of the brought tools; paying for used inputs, raw materials; paying for instruments provided by larger systems. There are few examples: paying for electricity or paying taxes to the state for securing laws, maintaining infrastructure and other things; payment for their personal work and their additional tools; paying for the work of other participants in the process. The employees' payment often includes not only their work and the work of the additional tools they have brought in, but also the costs of maintaining various large tools or systems carried out through workers, for example, taxes on education, medicine and the like. The more various systems or common tools of broad application are created in any territory, the higher will be the costs of any entities operating in this territory, since they will include the costs of maintaining local systems and public tools. Herewith, the individual remuneration is approximately the same everywhere. This is the objective mechanism of formation of so-called surplus value.

However, evaluating the labor, the work of additional production tools is often credited to workers, and therefore, it is considered necessary to allocate more resources for their personal consumption. Thus, K. Marx considered this issue among others. However, he was right that if the resource base is insufficient to ensure competition between owners, then the costs of maintaining such competition are not required and a transition to a centralized organization is necessary. Meanwhile, Marx suggested the elimination of competition and along with that the subsystem of individual owners, also in those countries where resources were sufficient to 
maintain competition. Practice often shows that collective ownership of the basic means of production was possible only where resources allow creating only centralized system of ownership, not a competitive one.

\section{Information}

As mentioned before, the function of the owner is the distribution of resources gained out of using of his property. Initially, this required receiving them physically, and then transferring them further. However, technology development provides increasingly sophisticated resource management mechanisms. First, information exchange mechanisms were developed, thereby a large owner can remotely learn about available incomes as well as give instructions on their distribution. At the same time, mechanisms for many responsibilities delegating have been evolved.

Exchange mechanisms have also been improved. There are universal services of time-delayed exchange of resources appeared, and they are called money. At first, the states were their guarantors, and metal properties and their limited quantity enabled their international use. Then paper money appeared, their guarantors also often were the states, and the relative value of deferred money exchange services of various states in international operations varies depending on the demand for them. In other forms, such as electronic payments, the general principle prevails. At the same time, you need to pay for using these services, like any others. There are no significant differences between money, as services for providing deferred exchange, from transport services, for example [36]. Although their significant importance for social systems often provokes their isolation in a special type of goods.

The more important a particular production tool and the broader its application is or the larger the other tools depended on it, the more resources and, therefore, money flow through it. Accordingly, there is a need of more information to manage it effectively. With the development and complication of production, increasing large information nodes appear, consolidating information from an increasing number of interconnected objects. An increase in the socalled "property inequality" and in the number of officials are directly related to it. The first is happening as the property consolidation leads to the integration of monetary volumes tied to property. The second is linked to the fact that an increasing amount of information needs to be analyzed, since with the growth of labor productivity, information flows increase faster than the growth in the number of employees. Meanwhile it is possible to estimate an average growth rate of production systems, like any others.

\section{Systems Growth}

As stated at the beginning of the article, we consider all systems as patterns in the resources flows. In addition, all resource flows in self-sustaining systems are mutually directional. On each flow node, various resources are exchanged between counterparties in systems. It was also pointed that all resources of the system are directed to increasing the stability of resource flows. It is important that the exchange take place in relatively equal volumes of resources that means that on average the volume of some "exchanged" resource is exchanged for the number of counter resources in the amount required to create exactly the "exchanged" volume of resource.

The evolution of systems is impossible without the expansion of resource flows, since otherwise any external fluctuation will disrupt them. Meanwhile, there must be a source for resource flows expansion. Let us try to find it.

Obtained earlier resources are directed to create a new structure, new patterns in flows, and to increase enthalpy. This new structure is aimed at increasing the flows of counter resources, and the counter stream created by it is equal to the resources invested in this structure. Thus, the total resources contained in the existing structure, its enthalpy, are equal in volume created by its final counter flow. In addition, the total counter flow is also aimed at creating a response structure, which will further increase the flow of resources to create a new structure. Let us try to describe the foregoing in formulas for two counter streams of resources. Let us designate the first resource as $\mathrm{n}$ and the second recourse as $\mathrm{k}$. Each cycle of resource exchange has two counter flows $E_{n}$ and $E_{k}$. The current flow of each resource $E_{[i]}$ in the exchange cycle $\mathrm{i}$ is equal to the previous resource flow in cycle $\mathrm{i}-1$, created by the then existing structure of the system containing $\mathrm{E}_{[\mathrm{i}-1]}$ resources, plus the resource flow of the new structure that was created in the previous cycle i-1. This structure is created based on the invested counter resources received in a previous cycle, in the $\mathrm{i}-2$ cycle, and is equal in volume to this $E_{[i-2]}$ stream. Thus, for two counter resources $n$ and $\mathrm{k}$, we have a system of two equations:

$$
\begin{aligned}
& \mathrm{E}_{\mathrm{n}[\mathrm{i}]}=\mathrm{E}_{\mathrm{n}[\mathrm{i}-1]}+\mathrm{E}_{\mathrm{k}[\mathrm{i}-2]} \\
& \mathrm{E}_{\mathrm{k}[\mathrm{i}]}=\mathrm{E}_{\mathrm{k}[\mathrm{i}-1]}+\mathrm{E}_{\mathrm{n}[\mathrm{i}-2]}
\end{aligned}
$$

Then the total flow $E_{[i]}$ through the system is equal to $E_{[i-1]}$ $+\mathrm{E}_{[\mathrm{i}-2]}$. We get that the growth of the total flow through the system grows according to the Fibonacci sequence, when each new member of the sequence is equal to the sum of two previous.

It is worth noting that many systems in nature in their development reflect this sequence [37, 38], which can be considered as indirect evidence of this model relevance.

\section{Social Production Growth}

Let us return to social systems, in particular to their economic component. K. Marx previously formulated a similar system of equations in the scheme of reproduction. Considering the general economic model, he divided the entire society production into the production of means of production and the production of means of consumption. Both production volumes in value terms are divided into investments in capital, labor costs and surplus value. 
However, in the K. Marx scheme, all dependencies take place only within the framework of one cycle.

Let us try to create an analogy to this scheme, but with a relationship between different cycles, similar to the system of equations for abstract systems given above. First, we determine those resources that need to be considered. It is convenient to take labor and material resources, as in fact $\mathrm{K}$. Marx did. Then investments in the structure of labor resources will be investments in information tools embedded in people. Therefore, this structure is aimed at increasing labor efficiency that means increasing flows of counter resources, that is material resources. The structure of material resources reflects the resources invested in material tools, including means of consumption. And although it is not intuitively obvious that the structure of material tools is aimed at increasing labor resources, however, its increased complexity will inevitably increase the requirements for the workers' qualifications, and therefore, for greater productivity of their labor. The latter, even if the number of workers decreases, will lead to an increase in the total flow of labor resources.

It is worthy to note, however, that if the structure of labor resources is aimed primarily at increasing the range of available resources, then the structure of material tools is aimed more at increasing the intensity of interaction with employees due to greater productivity. That, according to the model considered at the beginning of the article, means that in general there are fewer labor resources than available material tools.

Now let us designate material resources as $\mathrm{C}$, and labor as $\mathrm{V}$, then, by analogy with the previous system of equations, we get for all social reproduction the following:

$$
\begin{aligned}
& C_{[i]}=C_{[i-1]}+V_{[i-2]} \\
& V_{[i]}=C_{[i-2]}+V_{[i-1]}
\end{aligned}
$$

Such a formulation avoids the surplus value summand, and therefore, the question of its source. However, there is another difficulty appears: it is necessary to determine the duration of one cycle of social reproduction. It is obvious that it is more than a calendar year, since in a year the development of the material structure for changes in labor resources or a change in the information structure for changes in material resources will not have time to happen on a social scale. It is also possible that the cycle duration is not multiple of the calendar year, since many processes are not attached to it. Moreover, it could even be that the duration of the cycle of social reproduction is not constant, since the speed of many production processes accelerates with time significantly. However, if we are to evaluate, for example, according to the approximate time of the firearms proliferation in Europe or personal computers in the world, from the first finished prototype to widespread use, the duration of the cycle of public reproduction is about 30-40 years. The precise determination of this cycle duration requires considerable research, which is beyond the scope of this theoretical article.
It is also possible to compose a similar system of equations for any other systems if we precisely determine their resources exchanged and the duration of one exchange cycle. In a similar way, it is possible to describe the development of individual small social systems, such as, for example, commercial organizations or information communities. However, in most of them, the development will also consist, on the one hand, in complicating the structure of people of a certain area, and on the other hand, in a specific complication of the material structure, including the information component. For instance, the better consumers of any informational content know its content, the more complex and interesting the content may be, which is also will lead to the expansion of the relevant knowledge of the audience. Or for example, the deeper any scholars understand the essence of the processes under study, the more areas there are where they could apply their results. The latter, in its turn, will develop research areas.

Such examples could be given for more material areas, for instance, for production. Nevertheless, it would not chance the general principle. The development of any systems, not just social ones, occurs at the intersection of resource flows. The structure through which the exchange proceeds complicates on exchanging of the resources. The development of the structure comes at the expense of resources exchanged. In addition, there always will be one of the components of the exchange structure, which is aimed at expanding of the structure of the opposite component. Other component will be aimed at increasing the depth of the structure of the counter component. The system development rate in the absence of an outside interference is determined - the volume of resources invested in the overall structure, its enthalpy, grows according to the Fibonacci sequence.

\section{Conclusion}

This article briefly examined some of the rules that govern the systems, if they defined as patterns in resource flows. Moreover, it describes the process of specialization of system components, which is the source of the synergy effect. There were given some examples of how this process emerges in social systems, which are also reflect the social norms formation. Particular attention was given to consideration of the norms aimed at property rights protecting, which reflect the prevailing method of production organization.

Meanwhile, the social norms, including property rights, were assigned to human tools that are created by any social systems with a view to increase labor productivity. Such tools vary in scope of application, but all of them generate additional work when combined with human labor. Moreover, according to the model presented in the article, all tools are divided into material and information, composing the material structure and information structure of production. Information tools are characterized by the fact that their main holders are people, not only matter.

Information tools, as well as material ones, increase labor 
productivity. However, it is the informational structure of production that characterizes labor. Material tools could only complement the efforts of people in the labor process. In addition, material resources and human labor are two types of resources that are exchanged in the process of social production. During the process of exchange, material and informational structures expand. As in any other systems, the exchange of resources develops their structure, increasing the intensity of further exchange. Moreover, as it was shown in the article, an increase in the volume of resources invested in the structure of systems grows between exchange cycles with rates close to the Fibonacci sequence. The intensity of social production and the resources flows of smaller social systems are growing according to the same laws.

Thus, the article provides some suggestions for expanding the systems theory and shows examples of their application on social systems. In particular, the author of this article attempt to explain the revolutionary changes in history and to predict the characteristics of the upcoming similar changes in society based on the natural path of social systems development.

\section{References}

[1] Ruiz-Arenas, S., Horvath, I., Mejía-Gutiérrez, R., \& Opiyo, E. Towards the Maintenance Principles of Cyber-Physical Systems. Strojniški vestnik - Journal of Mechanical Engineering, 2014, 60 (12), pp. 815-831. doi: http://dx.doi.org/10.5545/sv-jme.2013.1556.

[2] Mitter, S. K. On System Effectiveness, Proceedings of Symposium on System Effectiveness, San Marino, Italy, 2002. Available online:

http://www.mit.edu/ mitter/publications/C29_onsystemeffect. pdf (accessed on 20 Jul 2019).

[3] Marin, D. G. Complexity and cost effectiveness measures for systems design. Manufacturing Complexity Network Conference, 9-10 April 2002, Downing College, Cambridge, UK. ISBN 1-902546-24-5.

[4] Sayama, H. (2002). Self-Protection and Diversity in SelfReplicating Cellular Automata. Artificial Life, 10: 83-98.

[5] Inglis, I. Review: The central role of uncertainty reduction in determining behaviour. Behaviour 2002, 137(12), pp. 15671599. doi:10.1163/156853900502727.

[6] Kliman, A. Reclaiming Marx's Capital: A refutation of the myth of inconsistency. Lanham, MD: Lexington Books, 2007.

[7] Costa-i-Font, J. and Frank, F. Social identity and redistributive preferences: a survey. Journal of Economic Surveys 2015, 29 (2). pp. 357-374. ISSN 0950-0804 DOI: 10.1111/joes.12061.

[8] Laborda Pemán, M., De Moor, T. A tale of two commons. Some preliminary hypotheses on the long-term development of the commons in Western and Eastern Europe, 11th-19th centuries. International Journal of the Commons 2013, 7 (1), pp.7-33. DOI: http://doi.org/10.18352/ijc.355.

[9] Thornton, P. H., Ribeiro-Soriano, d., Urbano, D. (2011). Socio-cultural factors and entrepreneurial activity: An overview. International Small Business Journal, 29 (2): 105 118.

[10] Ferraro, G. P. The cultural dimension of international business, 4th ed. New Jersey: Upper Saddle River, 2001.

[11] Triandis, H. C., Suh, E. M. (2002). Cultural influences on personality. Annual review of psychology, 53: 133-160.

[12] Sumpter, D., Brännström, A. Synergy in social communication. In: d'Ettore P, Hughes DP (eds) Sociobiology of Communication: An Interdisciplinary Perspective. Oxford: Oxford University Press, 2008, pp. 191-208 DOI: 10.1093/acprof:oso/9780199216840.003.0011.

[13] North, D. C. Understanding the Process of Economic Change. Princeton, NJ. Princeton University Press, 2005.

[14] Brugna, C., Toscani, G. Kinetic models of opinion formation in the presence of personal conviction. Physical Review E, 2015, 92 (5). doi: 10.1103/physreve.92.052818.

[15] Singh, P. Opinion formation models in static and dynamic social networks. Master's thesis / Doctoral dissertation, Rensselaer Polytechnic Institute, 2014. Available online: http://libproxy.lib.unc.edu/login?url=http://search.proquest.co $\mathrm{m} /$ docview/1622419234? accountid=14244 (accessed on $20 \mathrm{Jul}$ 2019).

[16] Albi, G., Pareschi, L., Toscani, G., Zanella, M. Recent Advances in Opinion Modeling: Controland Social Influence. Active Particles, Volume 1: Advances in Theory, Models, and Applications, 2017, pp. 49-98.

[17] Gneezy, U., Rustichini, A. A Fine Is a Price. Journal of Legal Studies 2000, Vol. 29: No. 1, Article 1. Available online: https://chicagounbound.uchicago.edu/jls/vol29/iss1/1 (accessed on $20 \mathrm{Jul} 2019$ ).

[18] Stern, J. Y. (2017). The Essential Structure of Property. Law Michigan Law Review, 115: 1166-1212.

[19] Rindos, D. The origins of agriculture: An evolutionary perspective. New York: Academic, 1984.

[20] Mason, R. (1982). Prehistoric mining in South Africa, and Iron Age copper mines in the Dwarsberg, Transvaal. Journal of the South African Institute of Mining and Metallurgy, 82 (5): 134-142.

[21] Kuijt, I. Life in Neolithic Farming Communities: Social Organization, Identity, and Differentiation. Kluwer Academic Publishers, 2002. ISBN 0-306-46122-6.

[22] Sentell, C. J. Freedom \& food, slavery \& agriculture: a philosophical ecology. Dissertation, Vanderbilt University. Nashville, Tennessee, 2015. Available online: https://etd.library.vanderbilt.edu/available/etd-03242015063056/unrestricted/Sentell.pdf (accessed on 20 Jul 2019).

[23] Engels, F. The origin of the family, private property and the state. London, England: Penguin Classics. 2010 (Original work published 1884).

[24] Meyers, B. Textiles and the Reformation. The Journal of Unitarian Universalist History 2001, 28 (Part 1).

[25] James, D. T., ed., The Rise of Merchant Empires: LongDistance Trade in the Early Modern World, 1350-1750. Cambridge, Cambridge University Press, 1990.

[26] Denzel, M. A. State and finance in the Holy Roman Empire 
from c. 1650 to c. 1800 . A survey, in 14th International Economic History Congress, session 106, 2006. Available online: www.helsinki.fi/iehc2006, scaricato il 24/5/2011 (accessed on $20 \mathrm{Jul} 2019$ ).

[27] Antunes, C. A. P., Polónia, A. Beyond Empires: Global, SelfOrganizing, Cross-Imperial Networks, 1500-1800, Leiden: Brill Academic Publishers, 2016.

[28] Ribeiro, A. S., Pinheiro, F. L., Santos, F. C., Polo'nia, A., Pacheco, J. M. Structural and temporal patterns of the first global trading market. R. Soc. open sci. 2018, 5: 180577. http://dx.doi.org/10.1098/rsos.180577.

[29] Lenin, V. I. Imperialism, the highest stage of capitalism, Reprint of the text given in V. I. Lenin, Selected works, English ed., Foreign Languages Publishing House, Moscow, 1970.

[30] Morck, R., Steier, L. The Global History of Corporate Governance: An Introduction. R. Morck (Ed.), A Global History of Corporate Governance. Cambridge, MA and Chicago, IL: University of Chicago Press, 2005, pp. 1-64.

[31] Brazhnikov, P. (2017). Social Systems: Resources and Strategies. Systems, 5 (4), 51.

[32] Hasegawa, T. The February Revolution, Petrograd, 1917: The End of the Tsarist Regime and the Birth of Dual Power (Revised, enlarged, and reinterpreted edition, Vol. Volume 149). Leiden: Brill, 2018.
[33] Smith, S. A. Red Petrograd: Revolution in the Factories, 1917-18. Cambridge: Cambridge University Press, 1983.

[34] Camfield, D. Revolution and Counter-Revolution in Russia, 1917-1928. Manitoba: The Geopolitical Economy Research Group, 2018. Available online: https://geopoliticaleconomy.org/wp-

content/uploads/2017/09/Camfield-Paper.pdf (accessed on 20 Jul 2019).

[35] Marx, K., Engels, F., Isaac, J. C., Lukes, S., Bronner, S. E., Tismaneanu, V., \& Sassen, S. The Communist Manifesto. Yale University Press, 2012.

[36] Brazhnikov, P. P. (2017). Review of the financial instrument from the perspective of systems theory. Trends Manag. 1: 8089.

[37] Grigas, A. The Fibonacci Sequence: Its history, significance, and manifestations in nature. Senior Honours thesis, Liberty University, Virginia, USA. Available online: https://digitalcommons.liberty.edu/cgi/viewcontent.cgi?article $=1347 \&$ context $=$ honors (accessed on 20 Jul 2019).

[38] Sinha, S. (2017). The Fibonacci Numbers and Its Amazing Applications. International Journal of Engineering Science Invention (IJESI), 6(9): 07-14. 